\title{
Competency Based Curriculum in Primary Schools in Kenya: Opportunities and Challenges of Implementation
}

\author{
Joseph w. Pale \\ School of Education, Masinde Muliro University of Science and Technology, P.O Box 190, Kakamega Kenya \\ Danson Amukowa \\ School of Arts and Social Sciences University of Kabianga P.O Box 2030 - 20200 Kericho Kenya
}

\begin{abstract}
The study was designed to investigate challenges facing the implementation of competency based curriculum $(\mathrm{CBC})$ in primary schools in Kenya. It dealt with the following aspects: Teacher's preparedness, availability and adequacy of teaching materials, level of collaboration between different government agencies and opportunities available for proper implementation of CBC in primary schools. The study employed a mixed research design. The sample for the study comprised 200 primary schools, 200 head teachers, 200 primary teachers and 4 Kenya national union of teachers sub branch secretaries drawn from Bungoma County. Data were collected using questionnaire, interviews and observation. It was then analysed both qualitative and quantitatively. The finding from this study reveal that the introduction of competency based curriculum into education system in Kenya primary schools was hurriedly done and not systematically planned and implemented; with minimal training of majority of teachers on its contents and teaching methods which tends to hinder their application of essential knowledge and skills of the curriculum. There was general lack of adequate approved textbooks for teachers and learners as well as instructional materials. Parents and other educational stakeholders' involvement and public participation in the curriculum reforms process was not adequate. Classrooms were overcrowded with pupils ranging from $70-100$ per stream. With these kinds of challenges, the success of the new curriculum is in doubt. It is therefore recommended that the ministry of education and other stakeholders should devote more efforts to the development of teachers' and head teachers' understanding of the CBC approach, assist in the construction of classrooms in primary schools and provision of adequate resources and facilities as well as sensitize and involve parents during parents teachers association (PTAS) meetings.
\end{abstract}

Keywords: competency based curriculum, Kenya, Parents' Teachers Association, Education stakeholders, Respondents.

DOI: $10.7176 / \mathrm{JEP} / 11-32-06$

Publication date: November $30^{\text {th }} 2020$

\section{Introduction}

Various authors have defined the concept of competency William G.Spady, (1977), defines competencies as indicators of successful performance in life - role activities (p.10).

Competencies involve the ability to create effective results in one's life. According to Block (1978), competencies means succeeding in existing social role structures and having the ability to create new roles for oneself in response to changing social conditions.

According to Jallow (2011), a competency is a statement of learning outcomes for a skill or body of knowledge. He adds that when students demonstrate a competency, they are demonstrating their ability to do something i.e they show the outcome of learning process.

Sullivan (2014), views competency as a set of skills, knowledge and behaviours that someone needs to have achieved in order to perform tasks, or activities at school and in the world of work.

Competency based learning begins by identifying specific competencies or skills, and enables learners to develop mastery of each competency or skills at their own pace. Learners can just develop just the competencies or skills they feel they need for which increasingly they may receive some form of validated recognition.

Competency based learning is particularly appropriate for adult learners with life experience who may have developed competencies or skills without formal education or training for those who started school or college and dropped out and wish to return to formal study., but want their earlier learning to be recognised, or for those learners wanting to develop specific skills but not wanting a full program of studies.

Competency based learning can be delivered through online, because many students taking such programs are already working or seeking work. A feature of most competency based programs is a partnership between employers and educators in identifying the competencies required, at least at high level. Some of the skills such as problem solving or critical thinking may be considered high - level but competency - based learning tries to break down abstract or vague goals into specific, measurable competencies.

Competency based curriculum adopts a learner centred pedagogy and emphasises on the development of competencies and appropriate application of skills and knowledge in real life context. 
Many countries around the world are carrying out extensive curriculum reforms to better prepare learners for the high education demands and job market requirement in the $21^{\text {st }}$ century.

British Colombia - a province in Canada, Finland and Scotland are examples of high - performing countries that demonstrate elements of competency based education within their systems. British Colombia adopted a curriculum that focus attention on students demonstrating competency on higher order skills that they need to succeed in their education and their lives.

Finland's education system is designed to foster student agency, responsibility and growth through self directed autonomous learning especially in the later high school grades. Its system ensures students master skills through performance - based assessment.

Scotland is part of the United Kingdom launched its "curriculum for execellence" in $2010-2011$ which embraces certain important elements of competence education. It focuses on formative assessment in the classroom, a "show what you know" and the needs of the holistic well-being of the child.

Trends in competency based curriculum has also emerged in East Africa. According to sessional paper No. 14 of 2012, the East African partner states adopted a policy of harmonizing their education systems that will shift focus from the standard curriculum design to the CBC and assessment approach (East African Community, 2012). In 2013, partner states in the community decided to put in place a harmonized curriculum which is competency based (East Africa community, 2014).

Tanzania introduced competency based curriculum in 2005 in secondary schools (World Bank, 2011). In 2006, competency based curriculum was introduced in primary. Education as well. The ministry of education and culture anticipated developing the education system that enables the Tanzanians to be sufficiently equipped with knowledge needed to completely and competitively solve the development challenges which face the nation (Tanzania ministry of Education and culture, 2001). However, five years later in 2012, after the implementation of the competency based curriculum in Tanzania, studies carried out by Mosha and Paulo and Tilya in 2014 on the compatibility between the competency based curriculum and the teaching methods found out that curriculum developers, book writers and teachers lacked clarity in the implementation of the competency based curriculum. More efforts was needed to be devoted to the development of teachers' and principals' understanding of CBC approach.

Other studies conducted by Makunja (2016) on challenges facing teachers in implementing CBC in Tanzania have confirmed that there is very minimal use of the $\mathrm{CBC}$ teaching approach in schools and that 80 percent of the teachers lack proper understanding of the approach and continue to use traditional knowledge - based teaching and learning methods, with assessment methods remaining the same as those used in assessing knowledge - based teaching and learning, while the teaching approach continues to be teacher - centred. Lack of adequate in service training for teachers was one of the major challenges affecting sufficient implementation of the curriculum - an indication of teacher unpreparedness and readiness in the use and application of pedagogical knowledge during teaching and learning process. The result further found that although teachers were willing to implement the $\mathrm{CBC}$, they lacked enough knowledge and understanding of the competency based curriculum.

The findings of the study conducted by Kya and Hung (2019) concur with those of Makunja and Mwandanji in (2015) where they established that the duration of the CBC training sessions in Tanzania was too short and ineffective to equip teachers with knowledge and skills about competency - based curriculum.

Rwanda shifted to the competency - based curriculum in 2015 in order to deal with scarcity in skills in the Rwandan education system laying its emphasis on science and technology.

Formal education was introduced in Kenya during the British colonial era. Between 1964 and 1985 the education cycle comprised seven years of primary school, four years of secondary school, two years of high school and three years of university education (7-4-2-3).

In January 1985, the 8-4-4 system of education was introduced to address concerns that the basic education previously provided lacked the necessary content to promote widespread sustainable self-employment. The reform was prompted by a change in the structure of the Kenyan education system. The reform was incidental and not initially anticipated. In 1981, the government set up an education commission, "The presidential working party on the second university in Kenya", with a mandate to advice on the establishment of the second university in Kenya. In the course of its deliberations, the commission advised the government that it would be practically wise to reform the country's education structure and curriculum. This culminated in the change of structure of education from 7 years of primary education, 6 years of secondary and 3 years of university education to 8-4-4 system.

In the 8-4-4 system learners were to take eight years in primary, four years in secondary school and four years of university education. Since its implementation in 1985, the curriculum has undergone several reviews. It was however felt by the majority of citizens that the current system of education is not fit for purpose. This was confirmed by the findings of a summative evaluation of primary and secondary education curricular and a national needs assessment study conducted by the Kenya Institute of Curriculum Development (KICD) in 2009 and 2016.

The Kenya vision 2030, which is a country's blue print for national development, also points towards the need to reform the country's education in order to equip citizens with the knowledge, skills, attitude and values to 
achieve the nation's social, economic and political aspirations. The current curriculum is too rigid and had limited opportunities to align basic education with children's career interests, aptitudes and abilities. The system seems to serve best those who score high grades at the secondary, and then proceed for higher education and take up whitecollar jobs. This seems to be the predominant pre occupation of the Kenyan education. Whereas the country requires learners who perform well and proceed to train for careers in medicine, engineering, law and other traditional careers, there are many children whose aptitude, interest and abilities lie in vocational education, arts, sports and music.

The integration of Kenya in the East African community (EAC) is another reason for the curriculum reforms. The five east African countries (Kenya, Uganda. Tanzania, Rwanda and Burundi) resolved to create the EAC. One of the objectives was to foster cooperation and integration. One way of achieving this was through promoting movement of goods and services across the five countries. Movement of labour required that the curriculum for the partner states was harmonised to enhance mutual recognition of certificates (EAC, 2007, P76). The standards and competencies require that all partner states reform their curricula structure, and examination systems to align them to the EAC frame work (EAC, 2012).

In a major departure from 8-4-4 system, the Government of Kenya launched 2-6-3-3-3 system of education perceived to be competent based curriculum in January 2017. It was designated to comprise two years of pre primary education, six years of primary education, three years of junior secondary education, three years of senior secondary education and three year of university education.

The objective of the Kenyan $\mathrm{CBC}$ is that at the end of each learning cycle every learner will be competent in the following seven core competency areas:

Communication and collaboration, critical thinking and problem solving, imagination and creativity, citizenship, learning to learn, self-efficacy and digital literacy. Competency - based curriculum places emphasis on competency development rather than on the acquisition of content knowledge. This means that the teaching and learning process has to change its orientation from rote memorisation of content to the acquisition of skills and competencies useful for solving real - life problems.

Teaching methods include role play, problem solving, projects, case studies and study visits and other learner - centred strategies. The teacher is then expected to switch from the role of an expert to that of a facilitator who guides the learning process. Learners are expected to take responsibility for their own learning through exploration and experience.

Moreover, the revised curriculum require teachers to frequently asses their learners using portfolios, classroom or field observation, projects, oral presentations, interviews and peer assessments. Teachers are also required to change from a norm-referenced to criterion referenced judgement of learners competencies to determine their progress. Teachers are also supposed to provide continuous, timely and constructive feedback so that students can know the strength and weaknesses of their performance. The introduction of CBC in Kenyan primary schools therefore, calls for a comprehensive change in the instructional approach in terms of teaching, learning and assessment and this requires changes in teacher training programmes in order to equip teachers (both pre service and in-service) with competencies that will enable them to effectively handle the challenges associated with CBC

Implementation in schools. It is with such kinds of preparations that the government of Kenya needed before roll-out of the CBC in January 2019 and that is why the ministry of education chief secretary Amina Mohammed indicated that the new competency based curriculum should be suspended until that time when all education stakeholders, government agencies and opportunities are available for its proper implementation.

However, Kenya initiated the implementation of the competency - based curriculum in 2017 in the absence of interactive and participatory approach of classroom teachers and district education personnel, curriculum specialist and other experts who are involved in the planning and implementation of education reforms. There was no research evidence that was conducted on the effectiveness of the new system, no comprehensive survey of international best practices was conducted before its adoption and roll out nor was there any research to support the argument that $\mathrm{CBC}$ is more effective than the current learning out comes - based curriculum (8-4-4) system.

There was no research and appointment of an education committee or commission which established the need for reform and identification of the problems in the existing system of education. Instead, the government went ahead and rolled out $\mathrm{CBC}$ for pre-primary and standard one to three without forming a national education policy makers who would formulate sessional paper which would guide and legalise the entire education reform process and furthermore, no review of the existing education (8-4-4) system had been undertaken by an education commission before the roll out. Many questions about the existing system were left un answered and include:-

What were the goals of 8-4-4 system? To what extent were those goals achieved or not achieved? What gaps existed in the system that necessitated overhaul of 8-4-4 system and which gaps needed specific address? The 84-4 system was borrowed from Canada and why is it that Canada is one of the worlds most advanced and technological advanced country economically?

Why are the Kenyan graduates from the purportedly failed 8-4-4 system inventive and innovative people in 
the world and adopt in nearly most fields of work?

According to Sossion W, (2017) secretary of Kenya national union of teachers, the implementation of CBC was hurriedly undertaken. The majority of teachers had not been sufficiently trained in $\mathrm{CBC}$ content and teaching methods.

Sossion asserts that most pre-primary teachers, as well as those for grades one to three had not received any training while those that did attend training workshops were inadequately trained by trainers and facilitators who were themselves incompetent in the delivery of CBC approach.

Sossion also pointed out that the introduction of technical and vocational courses in the school curriculum was a serious mistake as the purpose of basic education is not to train students but to make them trainable. Empirical studies show that competency based models are mainly applicable to vocational education and training due to the emphasis placed on standards of competence in occupational sectors.

Competence is the possession and demonstration of knowledge, understanding, skills, attitude and behaviour required to perform a given task to a certain described standard. The concept is therefore more useful in vocational education since the emphasis is on the ability of the students to perform a set of related tasks with high degree of skills.

\section{Statement of the problem:}

The government of Kenya launched competence based curriculum in January 2017. The objectives of the Kenyan $\mathrm{CBC}$ is that at the end of each learning cycle every learner will be competent in the following seven core competency areas: communication and collaboration, critical thinking and problem solving, imagination and creativity, citizenship, learning to learn, self-efficiency and digital literacy. CBC places emphasis on competency development rather than the acquisition of content knowledge. This means that the teaching and learning process has to change its orientation from rote memorization of content to the acquisition of skills and competency useful for solving real-life problems. The teacher is then expected to switch from the role of an expert to that of a facilitator who guides the learning process. The introduction of competency based curriculum in Kenya therefore, calls for a comprehensive change in the instructional approaches in terms of teaching, learning and assessment and this requires changes in teacher training programmes in order to equip teachers with competencies that will enable them to effectively handle the challenges associated with $\mathrm{CBC}$ implementation in schools. This means for effective curriculum delivery and provision of quality education, teacher capacity building, provision of learning resources and teacher training is fundamental. However before initiating these modalities and strategies, the government went ahead with the national roll -out of the CBC in January 2019. Thus the implementation of $\mathrm{CBC}$ was hurriedly undertaken while the majority of teachers have not been sufficiently trained in CBC content and teaching methods. Moreover those teachers that did attend training workshops were inadequately trained by trainers and facilitators who were themselves incompetent in the delivery of the CBC approach.

\section{Theoretical background:}

The study is guided by two theories including: John Hatties (2012) visible learning that emphasizes the role of the teacher in terms of the impact approaches adopted may have on students learning and Dewey's (1952) social constructivism that focuses on the need to adopt learner centred approaches in curriculum design and delivery.

\section{Research question}

The following are the questions that guided the study:

1. What are the features of the competency based curriculum (CBC)?

2. What is the state of teachers' preparedness for implementation of CBC in Kenyan primary schools?

3. What are the challenges that face the implementation of $\mathrm{CBC}$ in Kenyan primary schools?

4. What opportunities are there for proper implementation of $\mathrm{CBC}$ in Kenyan primary schools?

\section{Methodology}

The study describe the key features of competence based curriculum, the opportunities and challenges of its implementation.

The study adopted an exploratory research design. According to Robson (2002), an exploratory study is a valuable means of finding out what is happening, seek new insights, ask questions and to assess phenomena in a new light .

The study sampled 200 primary schools with 1 head teacher and 1 assistant teacher from each of the sampled schools. Four sub-branch secretaries from the Kenya national union of teachers were purposely selected to provide information on competency -based curriculum.

\section{Sample and sampling}

The sample for this study constituted teachers and executive branch secretaries of teachers union $(n=404)$ drawn 
from two hundred primary schools and four sub-counties.

\section{Data collection instruments}

The presentations received from the respondents were collected by use of questionnaire, interview and observation.

\section{Data collection and analysis}

Questionnaires were administered to the respondents. The information obtained from the questionnaires was supplemented by actual classroom observation to assess whether teachers are using $\mathrm{CBC}$ approaches in their teaching. It also sought whether teachers design effective learning activities that trigger child participation. Classroom observation also sought to find out whether teachers are able to focus on cross-cutting issues. The researcher used a check list that elicited information regarding child participation as key in CBC such as group work, brain storming, role play, share exercises and storytelling. From the observation carried, it was found out that $70 \%$ (280) of the respondents from the sampled schools were not emphasizing on the use of these techniques. This shows that children were not actively involved in the learning and teaching process.

Teachers complained that classes are overcrowded such that it is difficult to move around and interact with learners. According to $\mathrm{CBC}$ approaches, a teacher should be a facilitator giving room to learners to participate through group work, role play and this doesn't work well in big classes. Requirements from the checklist also sought whether teachers from the sampled schools prepare their lessons while focusing on cross - cutting issues that allow learners to broaden their thinking and understanding. The cross cutting issues includes: communication, and collaboration, critical thinking and problem solving, creativity and imagination, citizenship and digital literacy among others. Again the majority of the teachers (78\%) were not able to prepare a CBC lesson plans designed to facilitate acquisition of the competencies and at the same time retain subject and learning areas.

Requirements from the observation checklist stress on the use of formative assessment focused on the prescribed competencies. It sought whether teachers assess students frequently using the correct assessment methods such as portfolios, field observation, projects, oral preparation and interviews (Sturgis and Casey 2018). Findings indicated that $(70 \%)$ of the teachers had no sufficient knowledge of the assessment methods. The assessment Rubrics had unclear guidelines which makes giving learners assignment difficult.

Interviews were also conducted among 50 selected teachers and 4 representatives of the Kenya National Union of Teachers to identify the challenges they face in the implementation of the competency based curriculum and to, also offer some suggestions and opportunities for proper implementation of the new curriculum . Data collected were then analysed both qualitative and quantitatively. Findings from interviews and questionnaires showed a number of challenges as indicated and explained. The majority of the teachers $(80 \%)$ complained that they lacked proper training on the job. The courses offered during school holidays were too short. Teachers should be trained regularly through seminars and workshops so as to update their knowledge and skills. The training should last at least 3 to 6 months. Findings from the questionnaire indicated that textbooks and reference books were not delivered on time with schools starting the year without the necessary textbooks. Out of 400 teachers that filled the questionnaire, $240(60 \%)$ requested the government to provide sufficient teaching and learning facilities like text books and classrooms so as to allow effective implementation of competency based curriculum (CBC). The results from the questionnaires show that the majority of the teachers (70\%) find it difficult to adopt the new approach as they were trained using traditional teacher centred approach. The implications for these findings is that teachers' educational culture and training background hinder them to adjust to this new teaching and learning approach. Teachers needed time and training for proper implementation of the new curriculum.

\section{Findings}

The study establishes that $\mathrm{CBC}$ was not well planned and implemented. Most teachers have not yet clearly understood the new approach. There was minimal training of a majority of teachers on $\mathrm{CBC}$ contents and teaching methods. The findings confirmed that lack of properly trained teachers was one of the major challenges hindering effective implementation of CBC. This was indicated by $280(70 \%)$ of the respondents. Lack of teachers on the job training about CBC limit teachers' pedagogical knowledge and skills to apply competence based education approaches during teaching and learning process, hence hindering its effective implementation in primary schools. Short courses on $\mathrm{CBC}$ were provided, teachers taking three -five day training sessions but the time for training was too short and the coverage cannot provide the required $\mathrm{CBC}$ knowledge and skills.

It was noted that most trainings are organized in holiday when teachers have a right to their holidays. Some teachers therefore feel demotivated. They expressed the view that $\mathrm{CBC}$ trainings should be organized during school days.

The trainers/facilitators were incompetent themselves and had not properly conceptualized and understood the $\mathrm{CBC}$ hence were not able to facilitate the training. The majority $280(70 \%)$ of the respondents were not able to prepare a competence based lesson plan and even deliver lessons using $\mathrm{CBC}$ approaches. Teachers were observed 
using traditional instructional approach in teaching. They are very familiar with the old methodology and some feel more comfortable about keeping the same teaching document from the past years instead of adapting them to the new methodology. Lesson plans and schemes of work were too lengthy which required too much preparation and paper work hence taking more time. In addition, the only $\mathrm{CBC}$ trained teachers in a school either transferred or retired leaving the school with non or less trained teachers.

Teachers' educational culture and background was another area of concern. The findings reveal that $300(75 \%)$ of the respondents contested that their educational background ties them to the effective operationalization of CBC as they have been studying using traditional teacher centred approach and it is now very difficult for them to adopt the new approach since they lack experience. To adapt a new approach, teachers needed time, training and good working environment. Teachers' educational culture and background therefore hinder them to adjust to this new teaching and learning approach.

Actual observation was undertaken by the researcher as teachers were executing their lessons in classroom. It was noted that large class size posed a threat to the teacher while teaching. This was confirmed by $320(80 \%)$ of the teachers. The number of pupils in the classroom was too big for the capacity of the class causing overcrowding. It was observed that in some schools surveyed, the teacher - student ratio ranged from 1:90 or higher which is against the ministry's standard which require the ratio to be 1:45. In such situations teachers failed to implement CBC method.

Teachers complained that teaching using CBC method was not possible in a class of 90 pupils given that a teacher has to teach other different subjects. Classes were overcrowded in such a way that it was difficult for a teacher to move around and interact with pupils.

With the 100 percent transition, there was an acute shortage of teachers, with some schools, having only a few teachers which posed a challenge in the successful implementation of the new curriculum (Sossion 2017, Ondimu, 2018). The study established that large class size tends to effect pupil - teacher interactions and even prevent pupil - pupil exchange during sharing of materials and discussion in the class.

Competency - based curriculum generally requires small classes for teachers' to give personal attention to each learner. The evaluation of learning outcome is done for groups not for learners as individual. Teachers therefore fail to evaluate learners as individual with different needs.

\section{Results}

The study was designed to investigate challenges facing the implementation of competency - based curriculum in primary schools in Kenya alongside the opportunities available for proper implementation. The results indicate that the implementation of the competency - based curriculum (CBC) in Kenya was hurriedly done before most teachers were trained on its contents and learning materials. There was also a general lack of parental involvement in the $\mathrm{CBC}$ implementation due partly to the fact that a majority of parents do not understand what $\mathrm{CBC}$ is all about, their expectations, learners' assessments and grading. The study also established that most primary schools had inadequate classrooms needed for the successful implementation of competency - based education. With increased enrolment to meet the 100 percent transition, the classrooms were overflowing with large numbers of pupils thus straining the inadequate existing facilities.

\section{Limitations of the study}

The study utilised a sample of 200 primary schools in Bungoma County of western Kenya. Although the research sample was representative, it was not chosen at random.

\section{Conclusion and implications}

This study notes that the implementation of competency - based curriculum in Kenya was not well planned and implemented.

Research concludes that the implementation was hurriedly done before most teachers were trained on its content and learning materials. Inadequate training of teachers will hinder most of them from obtaining a solid base of essential knowledge needed. This study concludes that teachers' understanding of CBC is minimal. The majority of teachers (70\%) were not able to prepare a competency based lesson plan and even deliver lessons using $\mathrm{CBC}$ approaches. The adequate and relevant instructional materials which were to help teachers with in depth understanding of the new curriculum were not delivered to teachers in time before the roll out was done.

The sessional paper to guide the process was presented to members of parliament months after the roll out of the new curriculum, which was quite unprocedural. The involvement of parents and other education stake holders and public participation in the curriculum reform process were in adequate. The study also noted overcrowding of pupils in classes which adversely affected the implementation of the new curriculum. The government should assist in the construction of additional classrooms in primary schools to ease out congestion in classes. The ministry of education should embark on training program on preparing teachers on the new curriculum. There is need to constant and consistent training and evaluation about $\mathrm{CBC}$ implementation to change the teachers' perceptions. It 
was noted that for learning to take place it is important that teachers are fully prepared to facilitate learning in terms of lesson preparation, teaching and assessment. Parents and other education stakeholders' investment and public participation in the curriculum reform process were inadequate. There is need for sensitization and involvement of parents through the school committees and parents associations. There was a general lack of approved textbooks. The government distribution and delivery of textbooks had been delayed with some schools starting the year without the required textbooks. In conclusion, competency based learning is relatively new approach to learning design which is popular with employers. However it requires lot of commitment and dedication for it to yield the expected results. There is need for engaging all stakeholders to get involved and support it. Teachers are required to change their mind set for effective implementation of CBC. In addition, the fact that it is aligned to national development goals and the big four agenda, its implementation will give birth to generation of Kenyans whose mind set is geared towards being job creators as opposed to job seekers. It is hoped that the ministry of education and other stakeholders in the education sector will consider our suggestions for future improvement of the new curriculum.

\section{Acknowledgment}

I would like to thank Head teachers and teachers whose schools were used in this study for providing valuable information concerning the implementation of competency based curriculum in primary schools in Kenya. I am grateful to four sub - branch secretaries of the Kenya national union of teachers for their genuine support and valuable assistance during the time this study was conducted.

\section{References}

East African community (EAC) 2012 Regional Report on the harmonization of the East African. Education systems and training curricula Arusha, EAC.

East African community (2014), Harmonized Curriculum Structure and Framework for the East African community primary education, Arusha.

Dewey, J. (1952). Social Constructivism: Learner centred approaches in curriculum design and delivery.

Jallow, S S (2011), Competency -Based Curriculum; Teaching and assessing student competences, UNESCO BRADA Dakar, Senegal. Prepared for the Pan African Conference on teacher Education and Development (PACTED Lome, Togo 13-15 April 2011.

John Hatties (2012), Visible learning for teachers: maximising impact on learning.

Kya,H.E and Huang. F. (2019), Community Awareness for competency based curriculum. A case study of parent of public secondary students in Arusha, Tanzania, International Journal of Academic Management Science Research, Vol 3 NO 11.

Makunja and Mwandanji, (2015). Adopting competency-based curriculum to improve quality of secondary Education in Tanzania; Is it a dream or reality, International Journal of Education Vol 3 No 11.

Makunja, G (2016); challenges facing teachers in implementing competence -based curriculum in Tanzania: The case of community secondary schools in Morogoro

Municipality, the International Journal of Education and Social Sciences, Vol 3 No 5 pp 3037

Mosha, H. (2012). A study of learning materials used to deliver knowledge and skills of competency based curricula: Tanzania ouagdougou, Association for Development of Education in Africa (ADEA).

Ondimu, S.M. (2018). Teacher Preparedness for the implementation of the competency based curriculum in private pre - schools in North Dagoreti Sub County Nairobi city county Nairobi.

Sossion, w. (2017), Teacher preparedness for the implementation of the competency-based curriculum in preprimary and lower primary grades in Kenya. Nairobi Kenya National Union of Teachers.

Sturgis C. and Casey, K.(2018). Quality principles for competency based education. Vienna.

Tanzania ministry of education and culture (2001), Secondary Education Master Plan 2001-2005, Dar of as Salama.

William G Spady “Competency Based Education”; A Bandwagon in search of a definition Educational researcher 6 (1); 9-14 January 1977. 